\title{
Prediction of oxygen deficits associated with effluent inputs to the rivers of the Forth catchment
}

H. P. STOUT

Mr W. K. Tayler. Southern Water Authority, West Sussex Water and Drainage Division

During 1974-78 I worked for the Clyde River Purification Board on developing models to predict the effect of effluent discharges on the dissolved oxygen regime in the Clyde estuary. I also looked at the effect of effluent discharges to the Luggie Water-a tributary of the Kelvin.

64. When we started the modelling work in the estuary we assumed the rate constants given in reference 7 . The rate constant for the uptake of carbonaceous biochemical oxygen demand was the same as that given by the Author, but that for the conversion of ammoniacal nitrogen to nitrate nitrogen was rather less than that of $0 \cdot 26 /$ day used by him. We were not convinced that the rate constant for the nitrogenous oxygen demand was applicable to the Clyde because graphs drawn from survey data relating ammoniacal nitrogen to salinity in the lower reaches of the estuary where there was little intermediate input of ammonia appeared to indicate that ammonia was behaving conservatively. In an attempt to confirm this a mass balance exercise was carried out relating the amount of ammoniacal nitrogen and nitrate nitrogen entering and leaving the upper estuary. Nitrite was not considered as concentrations were generally small.

65. Such an exercise is difficult to carry out accurately and there may be inaccuracies involved, particularly in calculating the amount of material leaving the estuary where advection and dispersion mechanisms are important. Despite these reservations the mass balance exercise confirmed that there is little oxidation of ammonia at present occurring in the estuary. Calculated amounts of biochemical oxygen demand discharged to the estuary ranged upwards from about $80 \mathrm{t} /$ day and the mass balance showed little of this to escape the upper estuary during summer low flow conditions. In contrast the amounts of ammoniacal and nitrate nitrogen entering and leaving the estuary were about $14 \mathrm{t} /$ day and there was little difference between the amounts entering and leaving. This was true over a wide range of flow conditions.

66. A further factor to support the assumption of a lower rate constant for nitrification in the Clyde estuary than that given by the Author is the fact that the predicted dissolved oxygen concentration would be much lower than that observed if the rate constant of $0.26 /$ day were used. No figures are available for concentrations of organic nitrogen and this might affect the mass balance and require an increase in the nitrification

Paper published: Proc. Instn Civ. Engrs, Part 2, 1979, 67, Mar., 51-64. 
rate constant. However, I do not think this would make a large difference to our conclusions.

67. The Clyde is a heavily polluted estuary and receives only a small proportion of nitrified effluent; this may explain the low rate of nitrification. It certainly would seem that it is not possible to choose a general rate constant for nitrification and that each case has to be examined on its merits.

68. The results of the mass balance survey indicate that the rate constant generally assumed for the uptake of carbonaceous biochemical oxygen demand is of the right order for the Clyde estuary.

69. The observed oxygen sag in the Luggie occurred within $2-5 \mathrm{~km}$ of the source of .pollution and was much greater than could be explained by considering carbonaceous biochemical oxygen demand alone. The figures obtained for theoretical oxygen deficits due to carbonaceous biochemical oxygen demand were of the same order as those given by the Author-typically about $0.5 \mathrm{mg} / 1$; the observed deficits reached a maximum of $4-5 \mathrm{mg} / \mathrm{l}$. Part of this could be explained by nitrification, but even so there would still be some discrepancy. However, there are other factors which affect the dissolved oxygen concentration. In particular there is a large amount of weed growth in the Luggie and there is certainly some diurnal variation in dissolved oxygen concentration during summer. I expect that the dissolved oxygen deficit may be to some extent due to bottom effects such as uptake by bottom deposits but I have no proof of this.

70. Was the Author able to explain theoretically the oxygen deficits of $60-70 \%$ saturation which he states are not uncommon in the rivers he considered?

71. Any future large increases in discharge are likely to be industrial and it is not likely that different industrial discharges will have the same oxygen uptake characteristics. As far as I am aware, there is little information available on the oxygen uptake characteristics of industrial wastes and these would have to be obtained or estimated for any proposed discharges of industrial effluent.

\section{Dr Stout}

The choice of values to be used for rate constants, or other parameters, is crucial to the use of an analytical model for predicting oxygen deficits. The position with regard to carbonaceous biochemical oxygen demand is reasonably well established but, as $\mathrm{Mr}$ Tayler points out, ammonia nitrogen oxidation demands are not so clear cut.

73. Nitrification is a two-stage process, with oxidation of ammonia to nitrite by Nitrosomosas followed by oxidation of nitrite by Nitrobacter. Both stages are temperature-dependent and proceed at different rates, but for practical purposes a single, first-order, rate constant is commonly used. The value of $0 \cdot 26 /$ day at $15^{\circ} \mathrm{C}$ assumes an adequate concentration of nitrifying bacteria, suitable nutrients and a sufficient supply of oxygen. If these conditions are not satisfied the reactions will be inhibited, and it is known, for example, that at oxygen concentrations below $5 \%$ saturation the oxidation does not take place, and may be replaced by reduction of nitrates and nitrites to nitrogen, with generation of oxygen. $\mathrm{pH}$ is also important, and under acid conditions activity may fall appreciably. ${ }^{7}$ It would be useful to know in more detail how the rate constant decreases as the oxygen concentration falls. The usual assumption that it takes its full value at concentrations above $5 \%$ saturation may not be strictly correct. For prediction purposes, however, the $0 \cdot 26$ /day value permits an indication of the maximum effect of a known input, even though this may not be realized fully in heavily polluted conditions.

74. The Luggi Water has been heavily polluted in the past and anaerobic decomposition products from the bottom mud are likely to contribute an indeterminate oxygen demand. Re-aeration may also be reduced by surface films of industrial chemicals, which will act to increase the oxygen deficits. Moreover, much of the effluent discharged is probably industrial organic material, which, as Mr Tayler says, may show 
different oxygen uptake characteristics. These can arise not only because the rate constants are different, but also because the oxygen demands for unit weight vary between chemicals. However, without detailed study it is difficult to analyse any particular situation.

\section{Reference}

7. Department of Scientific AND Industrial Research. Effects of polluting discharges on the Thames Estuary. HMSO, London, 1964, Water Pollution Research Technical Paper 11. 